\title{
Influence of antiviral therapy on survival of patients with hepatitis B-associated hepatocellular carcinoma undergoing transarterial chemoembolization
}

\author{
Bing $\mathrm{Li}^{1}$, An Chen ${ }^{2}$, Xilin $\mathrm{Du}^{2}$ and Jianxing Zhan ${ }^{3 *}$ \\ ${ }^{1}$ Department of General Surgery, Xi'an Worker's Hospital, Xi'an, Shanxi 710100, ${ }^{2}$ Department of General Surgery, Tangdu \\ Hospital, Xi'an, Shanxi, 710006, ${ }^{3}$ Department of Hepatobiliary Surgery, Xi'an Aerospace General Hospital, Xi'an, Shanxi \\ 710100, China
}

*For correspondence: Email: judny.mouttet9910@hotmail.com; Tel/Fax: 0086-029-85644119

\begin{abstract}
Purpose: To examine the prognostic value of antiviral therapy among hepatocellular carcinoma (HCC) patients undergoing transarterial chemoembolization (TACE).

Method: A total of 356 patients with HCC undergoing TACE were recruited for the purpose of current study. All the patients were categorized into two groups; antiviral $(n=132)$ and non-antiviral group $(n=$ 224). All the clinical and laboratory parameters were noted at baseline. Patients were then followed up for five years. The mortality rates in two groups were evaluated with Kaplan-Meier estimate.

Results: The average age of the participants was $51.2 \pm 6.17$ years. A majority (329; $92.4 \%)$ of the patients were male while females constituted only $7.6 \%$. During five years follow-up period, a total of $274(76.9 \%)$ died, with 89 patients belonging to the antiviral group while the remaining 185 patients were in the non-antiviral group. Mortality rate significantly differed between the antiviral and non-antiviral groups (67.4\% versus $82.5 \%, p=0.028$ ). The results of Cox regression demonstrated that being a smoker, low serum albumin, local ablation and resection decreased overall survival while female gender, antiviral therapy, and early tumor site-node-metastatis (TNM) staging increased overall survival. Conclusion: Antiviral therapy for underlying hepatitis B in HCC patients undergoing TACE prolongs overall survival and prevents or delays reactivation of tumor.
\end{abstract}

Keywords: Cancer, Chemoembolization, Hepatitis, Hepatocellular carcinoma, Transarterial chemoembolization (TACE)

Tropical Journal of Pharmaceutical Research is indexed by Science Citation Index (SciSearch), Scopus, International Pharmaceutical Abstract, Chemical Abstracts, Embase, Index Copernicus, EBSCO, African Index Medicus, JournalSeek, Journal Citation Reports/Science Edition, Directory of Open Access Journals (DOAJ), African Journal Online, Bioline International, Open-J-Gate and Pharmacy Abstracts

\section{INTRODUCTION}

Hepatocellular carcinoma (HCC) is a primary liver cancer and among one of the most fatal and prevalent tumors all over the world. It is the fifth most prevalent type of cancer among human beings globally and the seriousness of disease can be attributed to the fact that it is ranked third for cancer associated fatalities [1] According to global cancer statistics, HCC is the most prevalent histological subtype that causes 70 -
$80 \%$ of total liver cancer burden [2]. In 2012, the incidence of liver cancer cases was estimated to be 782,500 cases while the number of mortality cases was estimated to be around 745, 500 cases. Surprisingly, $50 \%$ of both incident cases and mortal cases belonged solely to China [3]. China, one of the largest countries in Asia, accounts for the maximum prevalence of HCC with highest fatality rate associated with the disease. Cirrhosis related to hepatitis B and C virus is considered major cause of HCC. In the 
developed countries such as United States (US), United Kingdom (UK), Australia, Northern America and Japan, HCV is the prevalent cause of HCC while in Asian countries, especially China; HBV is the most prevalent reason of HCC [4]. Apart from viral factors, there are various environmental, host genetics and demographic factors that primarily contribute to the increasing risk of HCC [5]. Since hepatitis B virus (HBV) is a well-established viral factor of increased risk of HCC and poor prognosis of disease, it is therefore extremely crucial to manage the underlying HBV along with the prime liver disease.

Two decades ago, HCC was considered a rare disease that was diagnosed in advanced stages only and there were very limited palliative and therapeutic options [6]. However, with increased incidence and prevalence of the disease, various new treatments have been used for early screening as well as treatment of the disease. Among such advances, liver transplantation is considered as curative for selected patients while transarterial chemoembolization (TACE) as palliative treatment is extensively used for HCC [7]. TACE is a minor invasive procedure that is used to block hepatic artery and administer chemotherapy directly to the tumor site through a catheter. TACE is different from systemic chemotherapy since it involves direct delivery of chemotherapeutic agents to the liver tumor site only [8]. Since TACE is a locoregional therapy, the chances of HBV reactivation gets potentially higher with this therapy [9]. Recently few short term studies have shown that concomitant use of antiviral therapy with TACE could ultimately decrease the risk of HBV reactivation.

Despite various therapeutic treatments, there is no significant improvement observed in survival trends of HCC patients. [6] The possible reasons might involve reactivation of HBV after TACE in the long run. In the current study, the overall survival was estimated and compared between HCC patients undergoing TACE with and without antiviral therapy.

\section{METHODS}

\section{Ethical consideration}

The ethical approval for the study was obtained from the Research Ethical Review Board (RERB) of the Xi'an Worker's Hospital (ref no. XWR/RERB/2015/HR-053). Thet study was carried out in accordance with international ethics on human research [10]. A written permission was secured to obtain and describe the data. All patient information was anonymized and identification of study participants was not disclosed during analysis.

\section{Study participants}

From January 2009 to December 2011, hospital database was retrospectively retrieved to identify participants diagnosed with Hepatitis B surface antigen (HBsAg) HCC followed by TACE. Diagnosis of HCC was based on histological findings or the European Association for the Study of Liver (EASL) guidelines. Patients were followed up for the period of five years until December 2016.

\section{Baseline data}

Apart from demographic data, baseline examinations before TACE included complete blood count, serum liver tests, chest radiography and DNA quantification of serum hepatitis $B$ virus. The quantification of HBV DNA was performed via detection of $\mathrm{HB}$ surface antigen (HBsAg), HB surface antibody (HBsAb), HB e antigen ( $\mathrm{HBeAg}$ ), $\mathrm{HB}$ e antibody ( $\mathrm{HBeAb})$, antihepatitis $\mathrm{C}$ antibody (HCV Ab), HB core antigen $(\mathrm{HBcAg})$. Polymerase chain reaction (PCR) was used to detect HBV DNA viral load. The quantitative fluorescence PCR kit used had a lower detection limit of $100 \mathrm{IU} / \mathrm{ml}$. Both intraoperative interpretations and imaging were used to evaluate the characteristics of tumor, and tumor site-node-metastatis (TNM) staging according to the Union of international cancer control. Within 7 days of all initial examinations, all patients received TACE with the following chemotherapeutic agents (doses mentioned as per session dose; epirubicin $(60 \mathrm{mg})$ with or without mitomycin $(6 \mathrm{mg})$, lobaplatin $(50 \mathrm{mg})$, carboplatin $(300 \mathrm{mg})$ and floxuridine $(500 \mathrm{mg})$. No particular combination of chemotherapeutic agents was used. The choice of chemotherapeutic agent with dose of lipiodol emulsion and/or gelform was done on case to case basis. TACE cycles were recorded.

\section{Inclusion criteria}

The inclusion criteria for the current study were as follow: a positive $\mathrm{HB}$ surface antigen $(\mathrm{HbsAg})$, adequate baseline liver and renal function that was assessed via Child-Pugh grade $A$ and serum creatinine level $<124 \mathrm{micro} \mathrm{mol} / \mathrm{L}$, respectively and lastly good tolerance for TACE. All the patients selected for the current study had minimum follow-up of six months. The same clinical and laboratory data that was recorded at baseline before TACE were recorded during follow-up. 


\section{Exclusion criteria}

Patients with negative HBsAg, co-infection with other hepatic virus, human immunodeficiency (HIV) infection, inadequate functioning liver (Child-Pugh grade B/C), administration of hepatotoxic medications, interferon and/or corticosteroid (3 months prior to TACE), any other malignant disease other than HCC or severe no-malignant chronic illness, obstructive jaundice, hepatic encephalopathy were excluded. In order to rule out possible adverse outcomes of TACE, all patients who experienced severe complications after TACE or adverse effects immediately after TACE or at least within one month were excluded. Patients having follow-up of less than six months were also excluded from the study.

\section{Treatment}

\section{TACE method}

Transcatheter arterial chemoembolization was performed as follows: A catheter was inserted into the hepatic artery directly supplying blood to the tumor site. As catheter tip approached the tumor site, one or a combination of anti-cancer drugs mixed with lipiodol was injected slowly. Gelation sponge particles were injected in cases when chemoembolized artery did not show stagnant blood flow $[11,12]$.

The changes in load of HBV DNA after TACE were categorized into three groups [13];

1. HBV reactivation was defined as $\geq$ ten-fold increment in the load of HBV DNA as compared to the values at baseline or undetectable HBV DNA from baseline. Moreover, it might also be considered viral reactivation if there is more than $200 \mathrm{IU} / \mathrm{mL}$ after TACE.

2. HBV downregulation was referred to $\leq$ tenfold decline in HBV DNA when compared with baseline or absence of detectable level DNA from baseline and HBV DNA > $200 \mathrm{lU} / \mathrm{mL}$ at baseline before TACE.

3. Stability: Patients were categorized as stable if they don't fall in categories of HBV reactivation or HBV down-regulation.

\section{Subsequent treatment}

All the recruited patients were followed up and subsequent treatments such as hepatectomy, local ablation, liver transplantation or sorafenib were recommended after initial TACE. None of the patient in the current cohort received liver transplantation. The selection of subsequent therapy was done on the basis of patient characteristics and response to treatment.

\section{Oral antiviral therapy}

The choice of antiviral therapy was solely based on availability of drug. In the current study, entecavir and lamivudine were used as anti-HBV agents.

\section{Statistical analysis}

The normality of quantitative data was examined by Kolmogorov-Smirnov test. Measures of central tendency and dispersion were calculated for continuous data. Frequencies along with proportions (\%) were used for categorical variables. Group comparison was performed by Chi-Square test, Student's $t$-test or one-way ANOVA, where appropriate [14].

Cox proportional hazard models were estimated to determine the association of variables with overall survival, were used. The variables with significant univariate $p$-values were subjected to multivariate regression analysis (backward elimination logistic regression analysis). KaplanMeier estimates with log rank tests were carried out for survival analysis. Overall survival (OS) was estimated from the date of TACE initiation to the completion of follow-up or death, whichever occurred first.

All the analyses were carried out using SPSS version 20. A codebook for categorical variables was maintained where presence of an outcome was denoted as "one (1)" while absence was coded as "zero (0)". All statistical inferences were made by using $p<0.05$.

\section{RESULTS}

\section{Baseline data of participants}

The baseline clinico-laboratory characteristics of study participants are demonstrated in Table 1. A total of 356 patients (mean age: $51.2 \pm 6.17 \mathrm{yr}$ ) were recruited to participate in the current study. Majority $329(92.4 \%)$ of the patients were male while females constituted only $7.5 \%$ of study population. Out of 356 patients involved, 132 (37 $\%)$ patients had antiviral therapy in the form of nucleotide or nucleoside analogs; 73 (55.3\%) received Entecavir while remaining 59 (44.6\%) received Lamivudine only. Antiviral drugs were used for a median period of 23.5 months. Antiviral therapy related serious adverse effects were not observed and hence not mentioned 
here. With respect to laboratory parameters, bilirubin levels and prothrombin time were significantly higher in antiviral group while albumin was higher in the non-antiviral group. With respect to UICC staging system, maximum number of patients were in stage Illa (31.4\%) and IIIb $(27.8 \%)$ while only 11 (3\%) of patients belonged to stage IV.

A total of 101 (28.3\%) patients were $\mathrm{HbeAg}$ positive with majority $47(35.6 \%)$ patients belonged to the antiviral group. The mean baseline HBV DNA was significantly higher in antiviral group as compared to non-antiviral group $(p=0.00)$. This explains the use of antiviral therapy in high viral load patients. The higher viral load can also be observed with majority $(54.5 \%)$ of patients in the antiviral group undergoing $>1$ cycle of TACE while only $34.3 \%$ patients had $>1$ TACE cycle in the non- antiviral group ( $p=0.00)$. The proportion of local ablation was also more profound in the antiviral group than non-antiviral group $(29.5 \%$ versus $17.8 \%$, $p=0.04)$. With respect to chemotherapeutic agents, there was equal distribution between two groups.

\section{Changes in viral DNA load after TACE}

After the initial TACE, majority 252 (70.7\%) had stable HBV DNA while downregulation was observed in $62(17.4 \%)$ patients. Reactivation of HBV DNA after initial TACE was observed in total 42 patients. Out of these 42 patients, only 6 (4\%) HBV reactivation cases were observed in the antiviral group while the remaining 36 (16\%) cases of HBV reactivation were noted in the nonantiviral group $(p=0.00)$.

Table 1: Baseline characteristics of the entire study cohort

\begin{tabular}{|c|c|c|c|c|}
\hline Baseline characteristics & $\begin{array}{l}\text { Entire cohort } \\
\qquad(n=356)\end{array}$ & $\begin{array}{c}\text { Antiviral group } \\
\qquad(n=132)\end{array}$ & $\begin{array}{c}\text { Non-antiviral } \\
\text { group } \\
(\mathrm{n}=224)\end{array}$ & $P$-value \\
\hline Age & $51.2 \pm 6.17$ & $49.8 \pm 5.83$ & $52.6 \pm 6.52$ & 0.49 \\
\hline Male gender & 329 (92.4\%) & $123(93.1 \%)$ & 206 (91.0\%) & 0.08 \\
\hline Current smoking & $102(28.6 \%)$ & $36(27.2 \%)$ & $66(29.4 \%)$ & 0.07 \\
\hline \multicolumn{5}{|l|}{ Serum } \\
\hline Hemoglobin (g/L) & $135.9 \pm 9.85$ & $135.7 \pm 8.5$ & $136.1 \pm 11.2$ & 0.64 \\
\hline White blood cells & $6.36 \pm 1.74$ & $6.15 \pm 1.35$ & $6.57 \pm 2.13$ & 0.41 \\
\hline Platelets & $167.2 \pm 14.59$ & $163.4 \pm 10.5$ & $171.0 \pm 18.69$ & 0.06 \\
\hline \multicolumn{5}{|l|}{ Hepatic function } \\
\hline Serum albumin (g/L) & $38.9 \pm 2.35$ & $38.8 \pm 2.5$ & $39.1 \pm 2.2$ & 0.04 \\
\hline Total bilirubin (g/L) & $17.6 \pm 4.9$ & $18.5 \pm 5.3$ & $16.7 \pm 4.5$ & 0.03 \\
\hline Prothrombin time (sec) & $12.3 \pm 3.9$ & $12.5 \pm 3.6$ & $12.1 \pm 4.2$ & 0.04 \\
\hline APTT (sec) & $27.5 \pm 3.6$ & $27.9 \pm 3.9$ & $27.1 \pm 3.3$ & 0.12 \\
\hline $\mathrm{ALT}(\mathrm{U} / \mathrm{L})$ & $56.9 \pm 16.4$ & $61.5 \pm 14.3$ & $52.3 \pm 18.5$ & 0.06 \\
\hline AST (U/L) & $85.35 \pm 29.5$ & $89.5 \pm 22.5$ & $81.2 \pm 36.5$ & 0.06 \\
\hline \multicolumn{5}{|l|}{ Hepatitis B } \\
\hline HbeAg positive & $101(28.3 \%)$ & $47(35.6 \%)$ & $54(24.1 \%)$ & 0.04 \\
\hline HBV DNA $\left(\log _{10} \mathrm{IU} / \mathrm{ml}\right)$ & $5.01 \pm 1.61$ & $5.61 \pm 1.82$ & $4.42 \pm 1.41$ & 0.00 \\
\hline \multicolumn{5}{|l|}{ TNM staging } \\
\hline I & $67(18.8 \%)$ & $22(16.7 \%)$ & $45(20.1 \%)$ & 0.02 \\
\hline II & $41(11.5 \%)$ & $23(17.4 \%)$ & $18(8.04 \%)$ & 0.00 \\
\hline Illa & $112(31.4 \%)$ & $45(34.1 \%)$ & $67(29.9 \%)$ & 0.04 \\
\hline $\mathrm{IIlb}$ & $99(27.8 \%)$ & $28(21.2 \%)$ & $71(31.7 \%)$ & 0.03 \\
\hline IIIc & $26(7.3 \%)$ & $8(6.0 \%)$ & $18(8.0 \%)$ & 0.73 \\
\hline IV & $11(3.0 \%)$ & $6(4.5 \%)$ & $5(2.2 \%)$ & 0.27 \\
\hline TACE cycles $(>1)$ & $149(41.8 \%)$ & $72(54.5 \%)$ & $77(34.3 \%)$ & 0.00 \\
\hline \multicolumn{5}{|l|}{ Subsequent therapy } \\
\hline Local ablation & $79(22.1 \%)$ & $39(29.5 \%)$ & $40(17.8 \%)$ & 0.042 \\
\hline Resection & $37(10.3 \%)$ & $13(9.8 \%)$ & $24(10.7 \%)$ & 0.58 \\
\hline Sorafenib therapy & $21(5.8 \%)$ & $8(6.0 \%)$ & $13(5.8 \%)$ & 0.95 \\
\hline \multicolumn{5}{|l|}{ Chemotherapeutic agent } \\
\hline 1 & $93(36.3 \%)$ & $31(23.4 \%)$ & $62(27.6 \%)$ & 0.82 \\
\hline$>2$ & $263(73.8 \%)$ & $101(76.5 \%)$ & $162(72.3 \%)$ & 0.73 \\
\hline
\end{tabular}


Table 2: Changes in HBV DNA after TACE

\begin{tabular}{lccc}
\hline $\begin{array}{l}\text { HBV DNA } \\
\text { status }\end{array}$ & $\begin{array}{c}\text { Total } \\
\text { patients } \\
(\mathbf{n}=356)\end{array}$ & $\begin{array}{c}\text { Antiviral } \\
\text { group } \\
(\mathbf{n = 1 3 2})\end{array}$ & $\begin{array}{c}\text { Non- } \\
\text { antiviral } \\
\text { group } \\
(\mathbf{n = 2 2 4})\end{array}$ \\
\hline Reactivation & 42 & $6(4.5 \%)$ & 36 \\
& $(11.7 \%)$ & 101 & $(16 \%)$ \\
Stable & 252 & 151 \\
& $(70.7 \%)$ & $(76.5 \%)$ & $(67.4 \%)$ \\
Downregulation & 62 & 25 & 37 \\
& $(17.4 \%)$ & $(18.9 \%)$ & $(16.5 \%)$ \\
\hline
\end{tabular}

\section{Overall survival in the entire cohort}

A total of $274(76.9 \%)$ died during follow-up period. Out of the 274 mortal cases, 89 cases belonged to the antiviral group while 185 patients died from the non-antiviral group. The mortality rate was significantly different between antiviral and non-antiviral group (67.4\% versus $82.5 \%$, $\mathrm{p}$-value $=0.028$ ). The overall survival rates for the entire cohort at 1, 2, 3, 4, 5 years were 50, 33.1, 23.5, 19.6 and $13.4 \%$, respectively (Figure 1). In each year of follow-up, the survival rates for the antiviral group were higher than the nonantiviral group i.e. $1^{\text {st }}$ year $(56.8 \%$ versus 45.9 $\%), 2^{\text {nd }}$ year $(40.1 \%$ versus $29 \%), 3^{\text {rd }}$ year $(31.8$ $\%$ versus $18.7 \%), 4^{\text {th }}$ year $(27.2 \%$ versus 15.1 $\%), 5^{\text {th }}$ year (19\% versus $\left.10.2 \%\right)$. The median survival time was significantly higher for patients in antiviral group when compared to those in non-antiviral group (log rank $p$-value $=0.032$ )

\section{Factors associated with overall survival in the entire cohort}

All the clinical and demographic variables in Table 1 were subjected to univariate analysis. The significant univariate factors $(p<0.05)$ were tested by multivariate regression using backward elimination approach (age, male gender, smoking status, TNM staging, albumin, bilirubin, ALT, AST, antiviral treatment, local ablation, resection and prothrombin time). Multivariate analysis demonstrated male gender, smoking status and higher albumin level were risk factors of low overall survival rates while TNM staging and antiviral treatment were associated with increased overall survival rates (Table 3 ). For the purpose of regression analysis, TNM staging was divided into early and late staging with stage 1 and stage II classified as early TNM staging while stage III and IV were classified as late TNM staging. Table 3 shows that being smoker, low serum albumin, local ablation and resection decreases overall survival while female gender, antiviral therapy, early TNM staging increases overall survival.

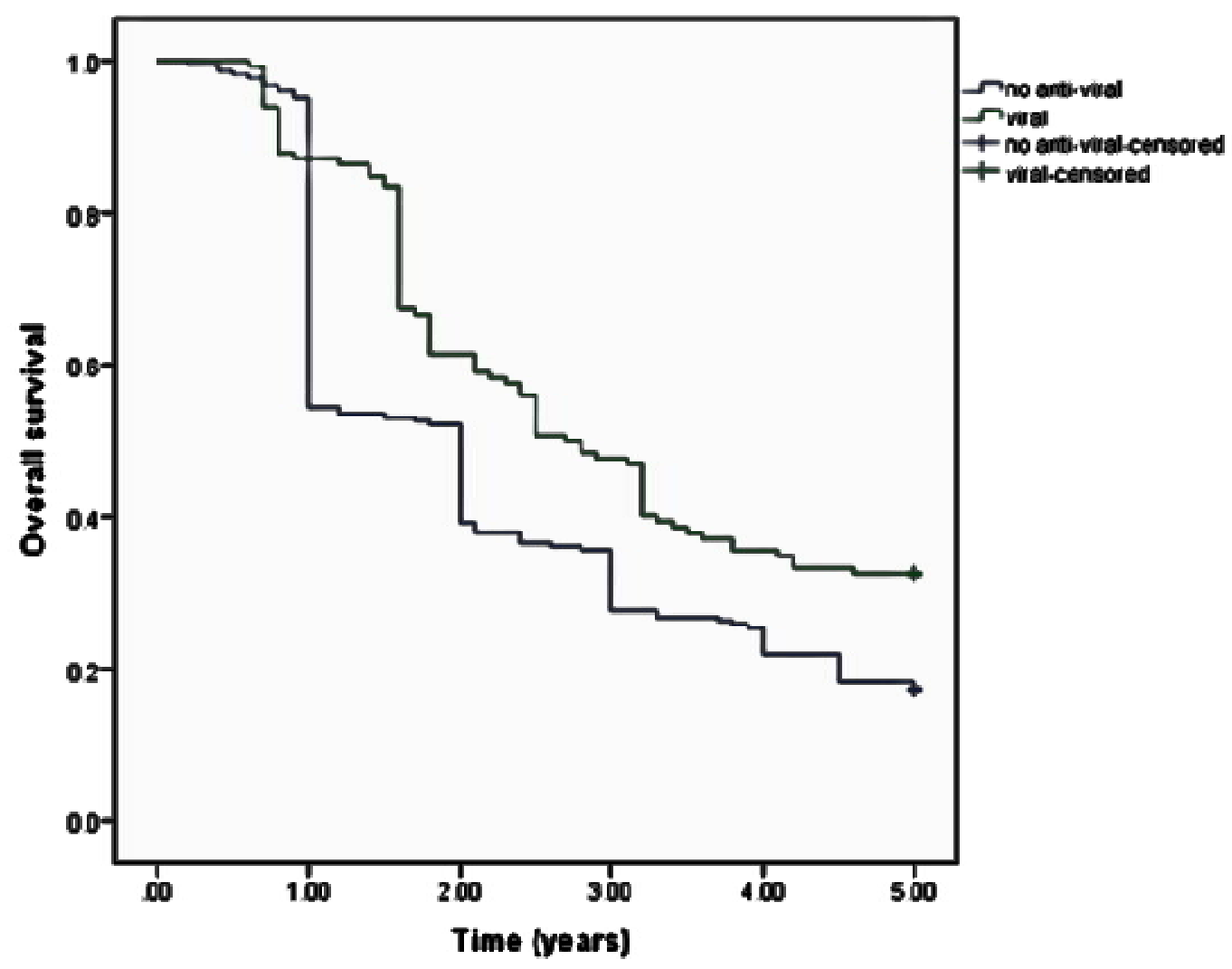

Figure 1: Kaplan-Meier curve comparing survival in HCC patients with antiviral treatment versus HCC patients without antiviral treatment (log rank $=0.03)$ 
Table 3: Cox regression analysis to deteermine variables associated with overall survival $(n=356)$

\begin{tabular}{lcccccc}
\hline Variable & \multicolumn{3}{c}{ Univariate analysis } & \multicolumn{3}{c}{ Multivariate analysis } \\
\cline { 2 - 7 } & $\boldsymbol{H R}$ & $\mathbf{9 5 \%} \boldsymbol{C l}$ & $\boldsymbol{P}$-value & $\mathbf{H R}$ & $\mathbf{9 5 \%} \boldsymbol{C l}$ & $\boldsymbol{P}$-value \\
\hline Old age & 0.75 & $0.63-0.97$ & $\mathbf{0 . 0 1 5}$ & 0.69 & $0.73-1.08$ & 0.724 \\
Female gender & 2.74 & $1.24-5.79$ & $\mathbf{0 . 0 2 7}$ & 2.44 & $1.15-6.73$ & $\mathbf{0 . 0 1 3}$ \\
Smokers & 0.65 & $0.28-0.51$ & $\mathbf{0 . 0 2 4}$ & 0.39 & $0.21-0.69$ & $\mathbf{0 . 0 4 8}$ \\
Serum albumin & 0.86 & $0.72-0.89$ & $\mathbf{0 . 0 3 8}$ & 0.61 & $0.57-0.92$ & $\mathbf{0 . 0 1 5}$ \\
Total bilirubin & 0.35 & $0.16-0.72$ & $\mathbf{0 . 0 4 2}$ & 0.42 & $0.43-1.08$ & 0.083 \\
PT & 0.62 & $0.46-1.02$ & 0.892 & & & \\
APTT & 0.29 & $0.91-1.32$ & 0.381 & & & \\
ALT & 0.68 & $0.48-1.09$ & 0.085 & & & \\
AST & 0.46 & $0.28-0.64$ & $\mathbf{0 . 0 4 1}$ & 1.08 & $0.96-1.04$ & 0.641 \\
HbeAg + & 0.26 & $0.97-1.42$ & 0.839 & & & \\
HBV DNA & 0.32 & $0.45-0.81$ & $\mathbf{0 . 0 4 6}$ & 0.49 & $0.84-1.91$ & 0.573 \\
TNM staging & 2.83 & $1.25-2.83$ & $\mathbf{0 . 0 0 2}$ & 2.62 & $1.12-3.79$ & $\mathbf{0 . 0 1 2}$ \\
(early) & & & & & & \\
TACE cycle <1 & 1.27 & $0.10-1.79$ & 0.273 & & & \\
Local ablation & 0.38 & $0.15-0.68$ & $\mathbf{0 . 0 0 3}$ & 0.31 & $0.09-0.59$ & $\mathbf{0 . 0 0 1}$ \\
Resection & 0.31 & $0.37-0.87$ & $\mathbf{0 . 0 0 1}$ & 0.25 & $0.24-0.73$ & $\mathbf{0 . 0 0 1}$ \\
Sorafenib therapy & 0.12 & $0.27-1.68$ & 0.438 & & & \\
Antiviral therapy & 3.24 & $1.57-4.28$ & $\mathbf{0 . 0 0 1}$ & 2.98 & $1.68-3.53$ & $\mathbf{0 . 0 0 2}$ \\
Chemotherapeutic & 1.09 & $0.92-2.08$ & 0.539 & & & \\
agent>2 & & & & & & \\
\hline
\end{tabular}

\section{DISCUSSION}

A preliminary literature search showed paucity of data on prognostic significance of antiviral therapy among patients with HBV associated HCC scheduled to undergo TACE. However, few studies have addressed the impact of antiviral drugs on the survival among post-resection HBV associated HCC patients [15-18] Most of these studies have shown that antiviral therapy improves prognosis of HCC patients after resection and increases overall survival. In a longitudinal cohort study, data of 4569 HBV related HCC patients was recorded and were subsequently categorized into two groups in order to investigate the risk of tumor recurrence between patients taking antiviral therapy and patients without antiviral therapy (518 versus 4051). The authors found that the antiviral treated cohort had a lower risk of HCC recurrence (20.5\% versus $43.6 \%$ ) and improved overall survival (10.6\% versus $28.3 \%)$ as compared to the non-treatment group [15].

In a meta-analysis of nine cohort studies including a total of 551 patients (204 with antiviral treatment, 347 without antiviral treatment), the authors concluded that antiviral therapy decreases tumor recurrence and improves overall survival in HCC patients undergoing curative treatments [16]. Despite abundant data on promising benefits of antiviral treatments in patients undergoing curative treatment for HCC induced by HBV, there is still paucity of data on impact of antiviral treatment on the long-term outcomes of patients with HCC having TACE.

On the basis of above mentioned gaps in the literature, the current study was designed to evaluate the effect of antiviral therapy in a cohort of hepatocellular carcinoma patients undergoing TACE. On the basis of antiviral therapy, patients were categorized into two groups i.e. HCC patients with and without antiviral therapy after TACE. The differences in clinical and demographic parameters were noted at baseline and factors contributing to overall survival were noted. Finally both patient groups were compared for overall upon completion of study.

In the current study, patients on antiviral therapy showed improved overall survival compared to the non-treatment group. Of the total 274 mortal cases, $32.4 \%$ cases belonged to the antiviral group while almost doubled cases (67.5\%) belonged to the non-antiviral group. The results of multivariate regression analysis showed antiviral therapy as the strongest independent predictor of overall survival with a HR of 2.98. This clearly shows that antiviral therapy offers survival advantage in HCC patients undergoing TACE. The exact mechanism by which antiviral therapy improves survival is unclear and several mechanisms have been proposed. One such proposed mechanism states that antiviral therapy improves survival mainly by reducing in HBV load i.e. decreased HBV DNA results in decrease viral replication [19]. As the viral load decreases, the genetic stability in hepatocytes is improved 
that helps further regeneration. In a metaanalysis, the authors reported the decrease in HCC recurrence with decreasing viral load [20]. In the current study, HBV reactivation was seen in $42(11.7 \%)$ patients after 6 months of initial TACE. Out of these 42 patients, 6 (14.2\%) patients were from the antiviral group while remaining $36(85.7 \%)$ patients were from the non-antiviral group. The exceptionally higher number of the non- antiviral patients with HBV reactivation confirms this mechanism.

Other proposed mechanism states that reduction of hepatitis activity and chronic inflammation in remnant liver by the antiviral therapy improves hepatic functional reserve and helps patients to tolerate subsequent HCC treatment [21]. In present study, $54.5 \%$ of patients with antiviral therapy received more than one TACE cycle compared to $34.3 \%$ patients with non-antiviral therapy who received more than one TACE cycle. At baseline, tumor stages and hepatic function were comparable in two groups, it is postulated that preservation of liver function by the antiviral treatment resulted in multiple cycles of TACE. Similar results have been shown by other recently conducted studies in HCC patients $[22,23]$.

Aside from antiviral therapy, other prognostic factors that improved overall survival included female gender and early TNM staging. It is a well-documented fact that HCC is more prevalent among male gender. Various studies have shown improved survival in female patients with reasons attributing to genetic differences between males and females [24,25]. In the current study, a total of 108 patients had early tumor staging. According to guidelines, TACE is recommended for patients with intermediate to advance TNM staging while surgical resection, ablation are recommended first line treatments for early stage tumor.

In present study these 108 patients underwent TACE as they had contraindications for surgery with major contraindication being tumor location. The results of multivariate analysis showed early stage TNM as significant prognostic factor of overall survival $(2.6 \mathrm{HR})$. Similar findings were reported by Chan et al. who studied the impact of antiviral therapy on survival of HBV related HCC patients after hepatectomy [26]. Authors found that patients with early stage tumor had increased overall survival as well as increased disease free survival rates. These findings suggest the initiation of antiviral therapy in patients with HCC at an early tumor rather than late tumor stage.

\section{Limitations of the study}

The main limitation associated with the current study is its retrospective nature. As the data was not collected prospectively, there were many missing variables. Moreover, patients with complications after TACE were not selected for the current study, therefore the results of the current study cannot be generalized for all HCC patients undergoing TACE. Lastly, patients with hepatic complications were also excluded. As most of HCC patients had several hepatic and other complications, more studies are required to explore the role of antiviral therapy in such cases. A prospective randomized controlled trial is needed to validate the findings of this study and to address the gaps presented in present study.

\section{CONCLUSION}

The findings of the study suggest improvement in overall survival with antiviral therapy following TACE among patients with HBV-related HCC. Therefore, it seems that HCC patients would benefit more from anti-viral therapy after after TACE in terms of enhanced patients' well-being and improved survival rate.

\section{DECLARATIONS}

\section{Acknowledgement}

The authors would like to thank biostatistics department of Tangdu Hospital, China for their assistance in statistical analysis.

\section{Conflict of Interest}

No conflict of interest associated with this work.

\section{Contribution of Authors}

The authors declare that this work was done by the authors named in this article and all liabilities pertaining to claims relating to the content of this article will be borne by them.

\section{Open Access}

This is an Open Access article that uses a funding model which does not charge readers or their institutions for access and distributed under the terms of the Creative Commons Attribution License (http://creativecommons.org/licenses/by/ 4.0) and the Budapest Open Access Initiative (http://www.budapestopenaccessinitiative.org/rea d), which permit unrestricted use, distribution, 
and reproduction in any medium, provided the original work is properly credited.

\section{REFERENCES}

1. El-Serag HB, Rudolph KL. Hepatocellular carcinoma: epidemiology and molecular carcinogenesis. Gastroenterol 2007; 132(7): 2557-2576.

2. Torre $L A$, Bray F, Siegel RL, Ferlay J, Lortet-Tieulent J, Jemal A. Global cancer statistics, 2015. CA: A Canc J Clinicians 65(2): 87-108.

3. Shin HR, Oh JK, Masuyer E, Curado MP, Bouvard V, Fang $Y Y$, Hong ST. Epidemiology of cholangiocarcinoma: an update focusing on risk factors. Cancer sci 2010; 101(3): 579-585.

4. Farazi $P A$, DePinho RA. Hepatocellular carcinoma pathogenesis: from genes to environment. Nat Rev Cancer 2006; 6(9): 674-687.

5. ElSerag, HB. Epidemiology of viral hepatitis and hepatocellular carcinoma. Gastroenterol 2012; 142(6): 1264-1273.

6. Forner A, Hessheimer AJ, Real MI., Bruix J. Treatment of hepatocellular carcinoma. Crit Rev Onco/Hematol 2006; 60(2): 89-98.

7. EISerag, HB Marrero JA, Rudolph L, Reddy KR. Diagnosis and treatment of hepatocellular carcinoma. Gastroenterol2008; 134(6): 1752-1763.

8. http://www.hopkinsmedicine.org/liver_tumor_center/treat ments/intraarterial_therapies/tace.html (Accessed 3 Feb 2017)

9. Peng JW, Lin GN, Jiang XM. Hepatitis $B$ virus reactivation in hepatocellular carcinoma patients undergoing transcatheter arterial chemoembolization therapy. Asia-Pac J Clin Oncoy 2010; 8(4): 356-361.

10. World Health Organization, \& Council for International Organizations of Medical Sciences. (2016). International ethical guidelines for health-related research involving humans.

11. Sergio A, Cristofori C, Cardin R, Pivetta G, Ragazzi R, Baldan A, Farinati F. Transcatheter arterial chemoembolization (TACE) in hepatocellular carcinoma (HCC): the role of angiogenesis and invasiveness. The Am J Gastroentero 2008; 103(4): 914-921.

12. Takayasu K, Arii S, Ikai I, Omata M, Okita K, Ichida T, Matsuyama $Y$, Nakanuma $Y$, Kojiro $M$, Makuuchi $M$, Yamaoka $Y$. Prospective cohort study of transarterial chemoembolization for unresectable hepatocellular carcinoma in 8510 patients. Gastroenterol 2006; 131(2): 461-469.

13. Lao XM, Wang D, Shi M, Liu G, Li S, Guo R, Yuan Y, Chen $M, L i J$, Zhang $Y$, Lin $X$. Changes in hepatitis $B$ virus DNA levels and liver function after transcatheter arterial chemoembolization of hepatocellular carcinoma. Hepatol Res 2011; 41(6): 553-563.

14. Khan YH, Sarriff A, Adnan AS, Khan AH, Mallhi TH, Jummaat $F$. Progression and outcomes of non-dialysis dependent chronic kidney disease patients: A single center longitudinal follow-up study. Nephrol 2017; 22(1): 25-34.

15. Wu CY, Chen YJ, Ho HJ, Hsu YC, Kuo KN, Wu MS, Lin JT. Association between nucleoside analogues and risk of hepatitis $B$ virus-related hepatocellular carcinoma recurrence following liver resection. JAMA 2012; 308(18); 1906-1913.

16. Wong JW, Wong GH, Tsoi KF, Wong VS, Cheung SS, Chong CN, Wong J, Lee KF, Lai PS, Chan HY. Meta-analysis: the efficacy of anti-viral therapy in prevention of recurrence after curative treatment of chronic hepatitis B-related hepatocellular carcinoma. Aliment Pharmacol Ther 2011; 33(10): 1104-1112.

17. Kuzuya T, Katano Y, Kumada T, Toyoda H, Nakano I, Hirooka $Y$, Itoh A, Ishigami $M$, Hayashi $K$, Honda $T$, Goto $H$. Efficacy of antiviral therapy with lamivudine after initial treatment for hepatitis $B$ virus-related hepatocellular carcinoma. J Gastroenterol Hepatol 2007; 22(11): 1929-1935.

18. Su CW, Chiou YW, Tsai YH, Teng RD, Chau GY, Lei HJ, Hung HH, Huo Tl, Wu JC. The influence of hepatitis $B$ viral load and pre-S deletion mutations on postoperative recurrence of hepatocellular carcinoma and the tertiary preventive effects by antiviral therapy. PloS One2017; 8(6): e66457.

19. Wong VW, Chan SL, Mo F, Chan TC, Loong HH, Wong GL, Lui YY, Chan AT, sung JJ, Yeo W, Chan HL. Clinical scoring system to predict hepatocellular carcinoma in chronic hepatitis $B$ carriers. J Clin Oncol 2010; 28(10): 1660-1665.

20. Qu LS, Liu JX, Kuai XL, Xu ZF, Jin F, Zhou GX. Significance of viral status on recurrence of hepatitis B-related hepatocellular carcinoma after curative therapy: A meta-analysis. Hepatol Res 2014; 44(7): 750 760.

21. Zhong JH. Nucleos (t) ide analogue therapy for HBVrelated HCC after hepatic resection: clinical benefits and unanswered questions. Tumuor Biol 2014; 12779-12784

22. Toyoda H, Kumada T, Tada T, Sone Y, Fujimori $M$. Transarterial chemoembolization for hepatitis $B$ virusassociated hepatocellular carcinoma: improved survival after concomitant treatment with nucleoside analogues. $J$ Vasc Interv Radiol 2012; 23(3): 317-322.

23. Yu SJ, Lee JH, Jang ES, Cho EJ, Kwak MS, Yoon JH, Lee HS, Kim CY, Kim YJ. Hepatocellular carcinoma: high hepatitis $B$ viral load and mortality in patients treated with transarterial chemoembolization. Radiol 2013; 267(2): 638-647.

24. Dohmen K, Shigematsu H, Irie K, Ishibashi H. Longer survival in female than male with hepatocellular carcinoma. J Gastroenterol Hepatol 2003; 18(3): 267272.

25. Altekruse SF, McGlynn KA, Reichman ME. Hepatocellular carcinoma incidence, mortality, and survival trends in the United States from 1975 to 2005. JClin Oncol 2009; 27(9): 1485-1491.

26. Chan AC, Chok KS, Yuen WK, Chan SC, Poon RT, Lo CM, Fan ST. Impact of antiviral therapy on the survival 
